\title{
フォノン輸送の視点からのナノ焼結体の熱伝導解析
}

\author{
堀 琢磨，塩見 淳一郎 \\ 東京大学大学院工学系研究科機械工学専攻, † 113-8656 文京区本郷 7-3-1.
}

\section{Thermal Conductance Analysis of Sintered Nanostructures from the Viewpoint of Phonon Transport}

\author{
Takuma HORI and Junichiro SHIOMI
}

\begin{abstract}
Dept. Mechanical Engineering, The University of Tokyo, 7-3-1 Hongo, Bunkyo-ku 113-8656, Japan.
\end{abstract}
Received December 15, 2014

\begin{abstract}
Over the last decade, there has been a great enhancement in efficiency of bulk thermoelectric materials by reducing lattice thermal conductivity with internal nanostructures. This includes sintered nanostructures, which has merit in applicability and scalability. While the material development so far has been rather empirical, for further improvement of the bulk nanostructured materials, the need for material design based on prediction of lattice thermal conductivity is growing. This paper reviews recently developed multiscale method to calculate lattice thermal conductivity of bulk crystalline nanostructures. The method seamlessly combines first-principles calculations of interatomic force constants, lattice dynamics calculations of intrinsic phonon transport properties, and Monte Carlo simulation of phonon Boltzmann transport through nanostructures. The method can handle phonon transport through a large system with randomly placed and shaped nanostructures, and thus it is sufficient to quantify how reduction of thermal conductivity of polycrystalline nanostructures depends on mean size and distribution of nano-grains. The results for sintered polycrystalline silicon nanostructure are presented.
\end{abstract}

\section{KEY WORDS}

Thermoelectrics, Sintered Nanomaterial, Phonon Transport, Thermal Conductivity, Monte Calrlo Simulation

\section{1 はじめに}

ナノテクノロジーの発展に伴い多様なナノ材料の合成や分 析が可能となっている。そうしたナノ材料はこれまで様々な 分野で応用されているが，その1つに熱電変換材料がある. 熱電変換の効率は $Z T$ と呼ばれる物性值によって決定され, その值が大きい程カルノー効率に近づく．ここで具体的には $Z T=S^{2} \sigma T / \kappa$ であり, $S$ はゼーベック係数, $\sigma$ は電気伝導率,

$T$ は絶対温度, $\kappa$ は熱伝導率である。したがって高い $Z T$ を得 るために, これまでパワーファクター $S^{2} \sigma$ の向上と平行して 熱伝導率の低下を目的とする研究が行われている.

ここで熱伝導は一般に電子とフォノン（量子化格子振動） をキャリアとしており, 特に半導体においてはフォノンによ る寄与が優位である。したがって半導体熱電変換材料の性能 向上のためにはいかにフォノンの輸送を阻害するかが課題と なる．古くからシリコンにゲルマニウムを固溶させる等の合 金化によってフォノンの散乱を促進する方法が用いられてき たが，近年はFig. 1 に示すようにナノ構造化によって作られ る界面によってフォノンの輸送を阻害し, 熱伝導率の低減を
実現する手法が提案されている1). 特にナノ構造の代表長さ をフォノンの平均自由行程（進行方向を変えずに移流する距 離）よりも短くする一方で電子の平均自由行程よりも長くす ることで，前者の輸送を阻害する一方で後者を犠牲にしない ことを狙う．熱電変換材料としてこれまで報告されているナ ノ構造は超格子 ${ }^{2)}$ やナノワイヤ ${ }^{3,4}$ 等があるが, 特にバルクの 結晶を粉砕した後に焼結して生成されるナノ焼結体はスケー ルアップに有利なため, これまで様々な材料に応用されてい $ろ^{5-10)}$.

ナノ焼結体を始めとするナノ構造化熱電材料の構造最適化 のためには，構造と熱伝導率の関係の予測が欠かせない. 例 えば，それぞれの基盤材料に対して熱伝導率の粒径依存性が 予測できれば，基盤材料の種類や粒径を選定する上で重要な 指針となる.これらの知見を得るために計算科学は有用な手 段であるが，そのためにはフォノンの輸送を微視的な視点か ら解析する必要がある。本稿では近年発展した基盤材料固有 のフォノンの振舞の計算手法およびそれを入力とするナノ構 造の熱伝導シミュレーション手法について解説する。また具 


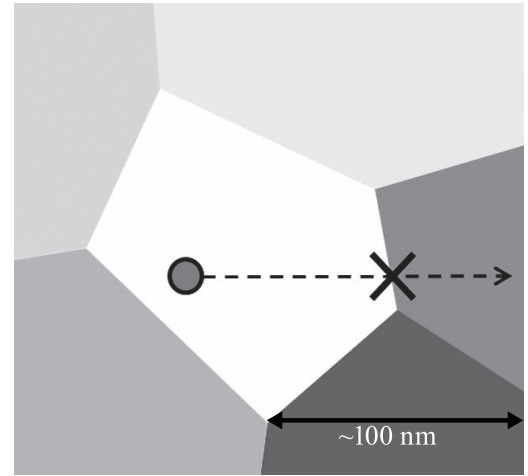

Fig. 1 Schematic illustration of the phonon-boundary scattering in a nanostructured material.

体的な例として，環境親和型の熱電変換材料の 1 つとして期 待されているシリコンナノ焼結体のフォノン輸送のシミュ レーションを紹介する.

\section{2 熱伝導解析の方法論}

2.1 マルチスケール手法による熱伝導率の計算

フォノンは格子振動であり, 様々な波数 $\mathbf{k}$, 分枝 $s$ を持っ た振動モードが存在する. また材料固有のフォノン分散関係 に従って，波数と分枝に対応する周波数 $\omega$ が定まる. 系が 熱的に平衡である時，ある1つのモードの占有数の期待值, すなわち分布関数はボースアインシュタイン分布 $f^{0}$ に従う が，温度勾配の存在する非平衡系ではフォノンが輸送される ため自明ではない. 式(1)に示すボルッマン輸送方程式はあ る空間 $\mathbf{r}$, 時間 $t$ における分布関数 $f$ の増減を表す.

$$
\frac{\partial f_{\omega s}(\mathbf{r}, t)}{\partial t}+\mathbf{v}_{\omega s} \cdot \frac{\partial f_{\omega s}(\mathbf{r}, t)}{\partial \mathbf{r}}=-\frac{f_{\omega s}(\mathbf{r}, t)-f_{\omega s}^{0}(\mathbf{r}, t)}{\tau_{\omega s}} .
$$

ここでvは群速度， $\tau$ は緩和時間である. 式 (1)の左辺第二項 はフォノンが群速度 $\mathbf{v} て ゙$ 移流することを, 右辺は緩和時間 $\tau$ に依存した頻度でフォノンの分布 $f$ が平衡分布 $f^{0}$ へ緩和する ことをそれぞれ表す。ここで，式(1)はバルクの系において は解析的に解くことができ, 熱伝導率は各々のモード（ $\omega お ~$ よびs）の寄与を足し合わせて

$$
\kappa=\frac{1}{3} \sum_{s} \int_{\omega} D_{\omega s} C_{\omega s} v_{\omega s}^{2} \tau_{\omega s} d \omega,
$$

となる ${ }^{11}$. ここで, $D$ はモードの数を表す状態密度であり， $C$ は比熱である. また $v=|\mathbf{v}|$ である. なお，平均自由行程 $\Lambda$ は群速度と緩和時間の積により $\Lambda=v \tau$ と表される。

上記のようにボルッマン輸送方程式には，材料固有のモー ドに依存したフォノンの群速度と緩和時間が含まれている. また，それぞれのモードの多頞を表す状態密度と比熱も材料 に依存する, 従って, 以上の群速度, 緩和時間, 状態密度, 比熱を総称したフォノン輸送物性の正確な計算が求められ る。また，そうしたフォノン輸送物性が得られても，ナノ焼 結体を始めとするナノ構造の熱伝導率を求める場合は境界条 件が複雑となるためボルツマン輸送方程式は解析的には解け ず, 数值的に解く必要がある。

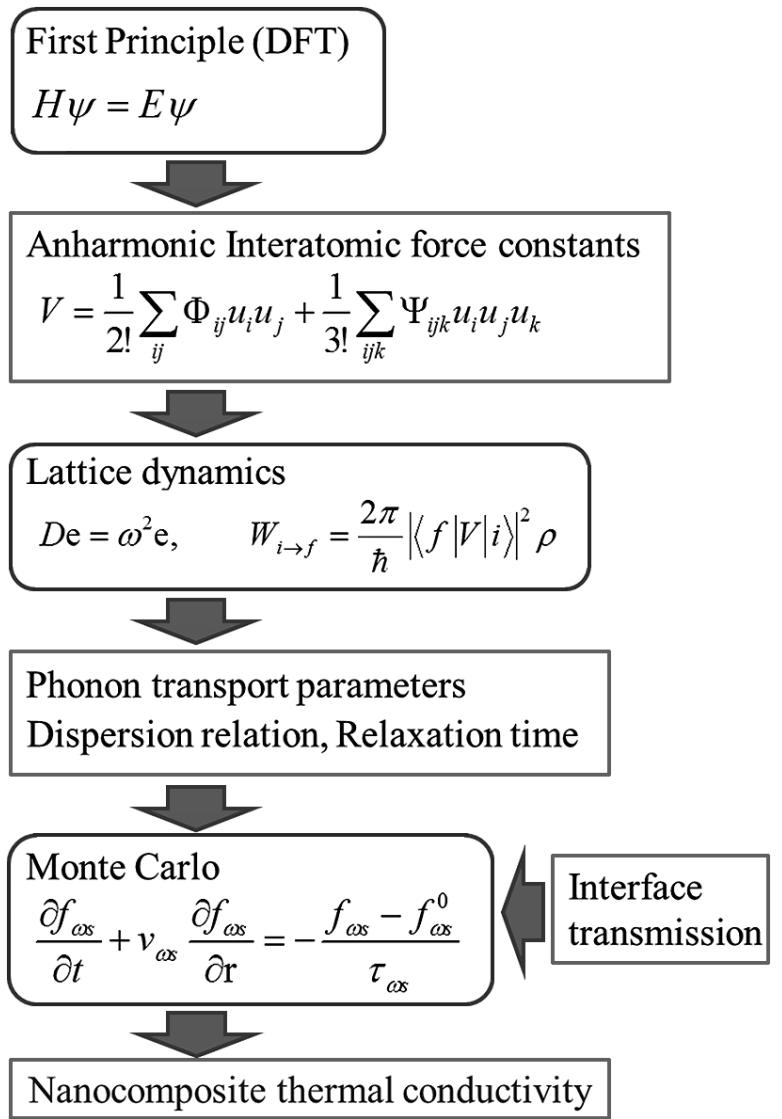

Fig. 2 Flow chart of thermal conductivity calculation of nanostructures from first principles.

そうした中，著者らのグループでは，第一原理計算に基づ く原子間力定数を用いて振動解析をすることでフォノン輸送 物性を得る手法を開発してきた。また，ボルッマン輸送方程 式の解法についても高速化方法などが近年になり発展してき た. そしてこれらを統合することにより Fig. 2 に示すような, 電子計算, 格子振動解析, フォノン輸送計算とマルチスケー ルに及ぶ数值計算によってナノ構造化熱電材料の熱伝導解析 が可能になった。この枠組みはフィッティングパラメータ等 の経験的な入力を必要としない点が長所である．以下では フォノン輸送物性の導出方法およびボルッマン輸送方程式に ついて述べる.

2.2 フォノン輸送物性

比熱, 群速度, 状態密度はフォノン分散関係を得ることで 計算できる。フォノン分散関係を得るためには調和的な（2 次の）原子間力定数から運動方程式を立て，それを固有值問 題として解く必要がある.この解析手法は一般に格子動力学 (Lattice Dynamics, LD) 法と呼ばれる ${ }^{11)}$. 比熱はフォノンの 周波数 $\omega$ によって $\omega$ とボースアインシュタイン分布から得 られ，群速度はフォノン分散関係を波数で微分することで計 算される.また，状態密度は波数空間から周波数空間へと変 換する際に波数空間上にあるモードの数によって決まる.

緩和時間の導出については近似した理論モデルが古くか ら報告されて来たが, 熱伝導率の実験值にフィッティング する必要があり，正確な值を得ることは困難である ${ }^{12)}$. そこ 
でフェルミの黄金律を利用し，フォノンのモード間の遷移 確率を求める手法が近年報告されている.この手法では上 記の LD 法と異なり調和的なものだけでなく非調和な（3 次 の）原子間力定数を取扱うことから一般に非調和格子動力学 (Anharmonic Lattice Dynamics, ALD) 法と呼ばれる ${ }^{11)}$.

上記のようにLD法およびALD法によるフォノン輸送物 性の導出では, 原子間力定数を求める必要があるが, 最近で は第一原理計算によって正確な值を求める方法が急速に発展 している，具体的な手法としては主に実空間変位法 ${ }^{13)}$ と密度 汎関数摂動理論を用いた方法 ${ }^{14)}$ などがある。これまでにこれ らの手法によって求めた原子間力定数から LD 法およびALD 法を用いて，シリコン結晶 ${ }^{13,15)}$ やハーフホイスラー合金 ${ }^{16)}$, 鉛テルル ${ }^{17)}$ を始め, 多くの材料 ${ }^{18)}$ のフォノン輸送物性が求め られてきた。 そうして得られたフォノン分散関係は非弾性中 性子散乱による測定值と一致し，またフォノン輸送物性を式 (2)に代入した結果得られる熱伝導率も測定值を再現するこ とが報告されている.

2.3 モンテカルロ法によるボルツマン輸送方程式の解

バルクの熱伝導率は 2.1 節のようにフォノン輸送物性を式 (2)に代入することで得られる。一方, 複雑な構造を持つ系 の場合は，それに応じた境界条件を設定しボルッマン輸送方 程式を解かなければならず, 数值的な解法が必要となる。こ こで一般的にボルツマン輸送方程式の解法として, 空間に メッシュを区切って解くオイラー的なものと, 粒子を空間中 に運動させて解くラグランジュ的なものに大別される. 前者 は統計的な平均をとる必要がなく解が得られる一方で, 後者 は複雑な境界条件の取り扱いが容易であるという利点を持 つ.一般にナノ構造におけるフォノン輸送の問題を解く際に は, この理由から後者の方法であるモンテカルロ法が適用さ れることが多い.

モンテカルロ法によってボルツマン輸送方程式を解く手法 は古くから希薄気体などに対して応用されていた ${ }^{199}$. 一方で 近年になりナノ構造中の熱伝導現象への関心が高まるにつ れて, フォノンに対しても適用されるようになってきてい る.フォノンのボルッマン輸送方程式を解いた例としては Peterson $^{20)}$ によるものが最初であるが, 線形的なフォノン分 散関係を用いた簡単なモデルであった。一方で Mazumder ${ }^{21)}$ らは分散関係を測定值から考慮するなど, より現実的なシ ミュレーションを行ったが, フォノンが散乱後にエネルギー

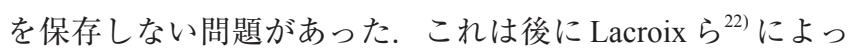
てキルヒホッフ則を保つ形で改善された。 またHao ら ${ }^{23)}$ は測 定值やシミュレーションによって求めたより現実的なフォノ ン輸送物性を用い,さらに周期的な熱浴を用いた境界条件を 導入するなど, シミュレーション技術を向上させた，後に， Peraud $ら^{24,25)}$ による非平衡成分のみを扱う手法の開発によっ てモンテカルロ法の速度が画期的に向上した.

以下に一般的なモンテカルロ法によるフォノン輸送の解法 について述べる.この方法では Fig. 3 に示すように境界に熱 浴が存在する非平衡状態の計算系において, 空間に分布した フォノンの移流および散乱現象の時間発展を計算する。 これ

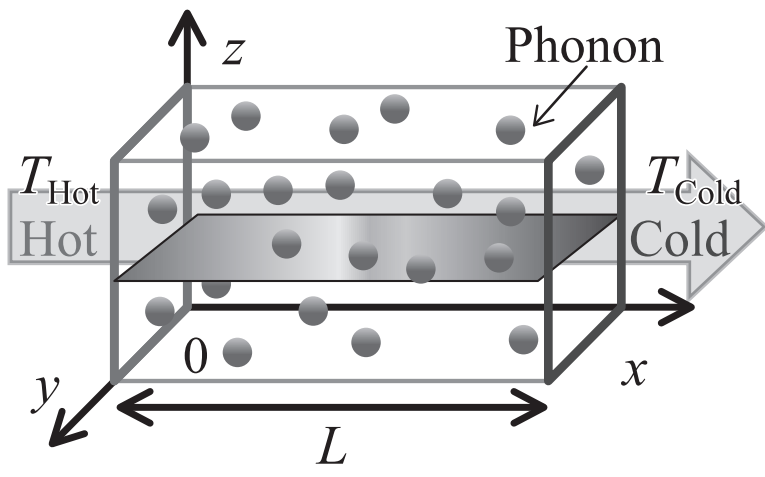

Fig. 3 Schematic illustration of Monte Carlo simulation for phonon transport.

により定常状態となった後の熱流束（フォノンの正味の輸送 エネルギー）と設定した境界の温度から実効的な熱伝導率が 得られる. シミュレーションの手順としては，まず境界条件 に応じて $x$ 方向の境界の熱浴からフォノンを生成する. 生成 するフォノンの周波数は状態密度とボースアインシュタイン 分布によって決定する. 次に, 式 (1)の左辺第二項の再現の ため, $\Delta t$ の時間刻みごとにフォノンをそれぞれの群速度で 移流させる。 この時, フォノンが計算セルの境界や内部構 造界面に接した場合, 反射や透過が起きる。移流後に式(1) の右辺のフォノン同士の散乱の再現のため, 確率 $P_{i}(\omega, s)=$ $1-\exp \left(-\Delta t / \tau_{\omega s}\right)$ で各フォノンを散乱させる.フォノンが散乱す る度に周波数, 偏向, 移流方向等の全ての状態を平衡分布に 従って生成し直す。

上述のようにフォノンが移流した際に計算セルの境界およ び内部の構造に接した場合, 反射や透過といった現象が起き る. 例えばナノ焼結体の場合, 粒界においてフォノンは透過 または反射するが，透過する確率を界面透過確率と呼ぶ．界 面透過確率はフォノンのモードに依存すると考えられてお り，これまで理論的な予測はあるが簡易的なものに留まって いる ${ }^{26,27)}$. 数值シミュレーションによって求める方法に関し ても例えば wave packet 法 ${ }^{28)}$, lattice dynamics 法 ${ }^{29)}$, 非平衡グ リーン関数法 ${ }^{30}$ 等が報告されているが, 界面が連続的に接続 されるなどの単純な界面構造に限られている。これは現実の 複雑な界面のモデリングが現在までできていないことに起因 する。また，界面をフォノンが透過または反射した後，フォ ノンは界面から放射されるがその放射角度は界面の粗さに よって決定されると考えられており ${ }^{31)}$, 例えば粗い界面の場 合は拡散的，すなわち入射角を記憶せずランダムな方向に放 射される。一方で滑らかな界面の場合，フォノンは入射角を 記憶し鏡面的に放射される.

\section{3 シリコンナノ多結晶体の熱伝導率}

焼結体のモンテカルロ法による解析の一例として, シリコ ンナノ焼結体の室温での熱伝導率を求めた。 なお, シリコン のフォノン輸送物性には上述の第一原理計算に基づいて得 られた值 ${ }^{13,15}$ を用いた。この方法では波数に応じたフォノン 輸送物性が得られるが，モンテカルロ法では一般に計算負 荷の都合上, 式(1)に示すように周波数に応じた值が必要と 
なるため周波数への変換を行った. シリコンはダイアモン ド構造を有し, 面心立方構造の単位胞の中に 2 つ原子を持 つ、そのため, 単位胞あたりの自由度は 6 となり, フォノン 分散関倸には横波音響（Transverse Acoustic, TA）モードが 2 つ, 縦波音響 (Longitudinal Acoustic, LA) モードが $1 つ$, 縦 波光学 (Longitudinal Optical, LO) モードが1つ, 横波光学 （Transverse Optical, TO）モードが2つ存在する。ただし，TO モードの熱伝導率への寄与は $1 \%$ にも満たない ${ }^{15)}$ ため考慮し ない。このようにして得られたフォノン輸送物性を式(2)に 代入することでバルクの熱伝導率は $133 \mathrm{Wm}^{-1} \mathrm{~K}^{-1}$ となる.

計算系には Fig. 4 のようにナノ焼結体を想定し，単純立方 構造の系とボロノイ図を用いた複雑な系をそれぞれ用意し た。ここで，ボロノイ図とは空間に配置した母点の間に垂直 二等分面を引くことによって作られる構造である。ただし， 母点をランダムに決定した場合，その粒径分布は現実に観察 される対数正規分布にならないことが知られる. そのため, 遺伝的アルゴリズム ${ }^{32)}$ を用いて母点の位置を調節し， Fig. 5 に示すように対数正規分布の広がりを表す $\sigma_{\ln }$ を $\sigma_{\ln }=0.35$ と した場合の粒径分布を再現した。ここで，粒径は各粒の体積 の三乗根によって定義した。 なお，単純立方構造ではその対 称性を利用し実際にはより小さな系での計算を行った。

それぞれの界面でのフォノンの透過確率 $t$ は上述のように 明確でないため, 以下の式(3)に表せる形に仮定した ${ }^{33)}$.

$$
t(\omega)=\frac{1}{\gamma \omega / \omega_{\max }+1} .
$$

ここで, $y$ はフィッティングパラメータで, $\omega$ はフォノンの 周波数, $\omega_{\max }=96 \mathrm{THz}$ は最大周波数である. サーモリフレク タンス法による測定によって得られた焼結界面熱コンダクタ ンス $\left(1 \mathrm{GWm}^{-2} \mathrm{~K}^{-1}\right)^{34)}$ を再現するようにランダウアーの式 にもとづいて $\gamma$ の值を求めたところ， $\gamma=2.4$ を得た。なお， 計算セルの境界ではフォノンは一切透過せず反射するよう設 定した。また，フォノンは界面に接触した際，透過不透過に 関わらず，これまでの方向を失いランダムな方向に放射され るように設定した。シミュレーション条件として，高温側 と低温側の熱浴の温度 $T_{\mathrm{Hot}}, T_{\mathrm{Cold}}$ をそれぞれ $T_{\mathrm{Hot}}=300.01 \mathrm{~K}$, $T_{\text {Cold }}=299.99 \mathrm{~K}$ とし, ふく射と同様にフォノンを放射させた.

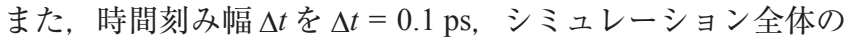
ステップ数を 20,000 ステップとし, 熱流束の值は十分に収 束したステップ数から平均の值を求め, 境界に課した温度と 併せて実効的な熱伝導率を求めた.

計算結果を Fig. 6 に示す。この図から単純立方構造におい て粒径を小さくすることで熱伝導率の大幅な低減が可能であ ることを定量的に示した．また，単純立方構造に比べボロ， イ図を用いた現実的な構造の方が熱伝導率は高くなった。こ れは粒径にばらつきのある場合，確率的に大きな粒の中を フォノンは通る傾向があり，そうした粒は界面が少ないため 散乱の頻度がより少なくなり熱抵抗が小さくなるからであ る。このように，モンテカルロ法を用いてフォノンの輸送問 題を解くことによりシリコンナノ焼結体を想定した系の構造 に依存した熱伝導率を求められる。 (a)

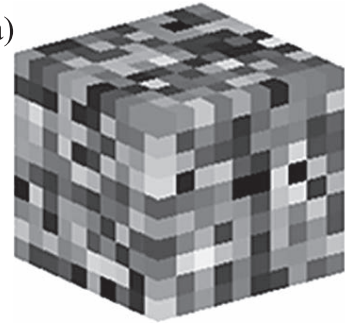

(b)

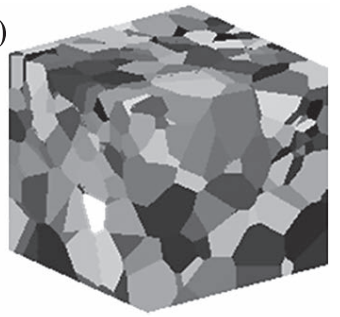

Fig. 4 Model of a polycrystalline nanostructure: (a) simple cubic and (b) modified Voronoi diagram.

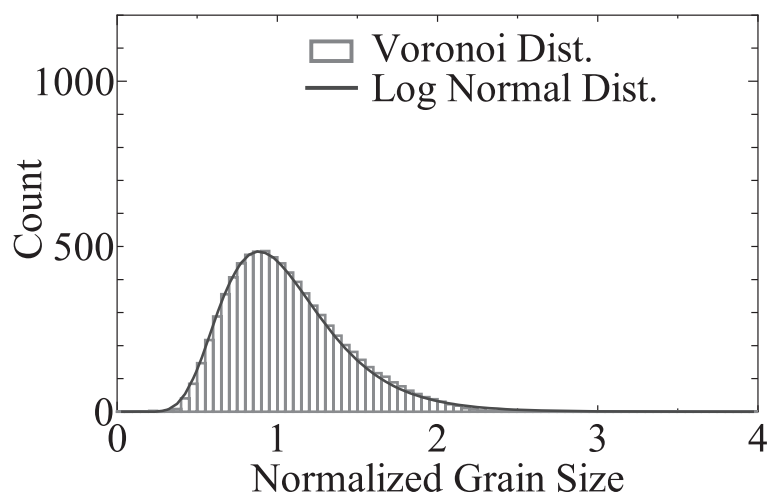

Fig. 5 Grain size distribution of modified Voronoi diagram.

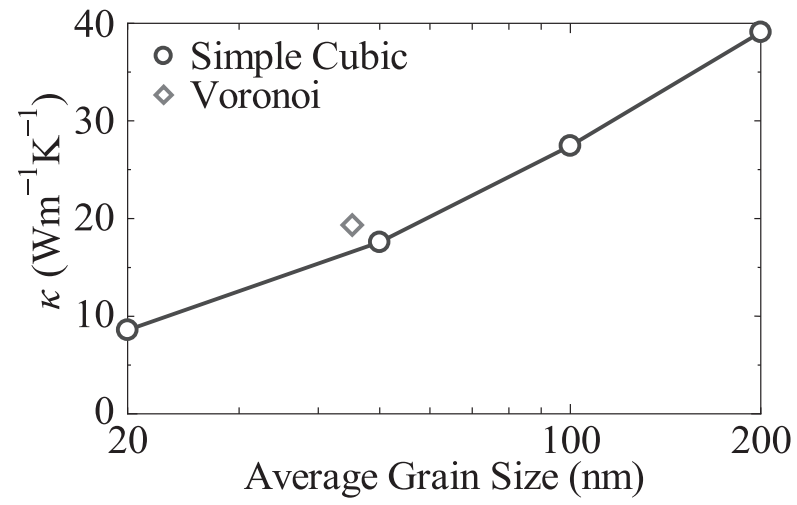

Fig. 6 Grain size and distribution dependence on thermal conductivity of polyscrystalline nanostructure.

\section{4 今後の展望}

本稿では熱電変換材料としてのナノ焼結体において，熱伝 導率を予測するためのマルチスケールのシミュレーション手 法を紹介した。こうした手法は今後も熱伝導率の予測を目的 としてょり多様な材料, 構造に対して適用されることが期待 される。一方で，より厳密かつ応用性の高い熱伝導率計算を 実現するためには様々な課題が残っている。例えば，マンガ ンシリサイドなどの単位胞内に膨大な数の原子を持つ材料に ついては計算負荷の都合上，そのフォノン輸送物性を求める ことは困難であるため, 今後の計算機性能の発展を待つ以外 にも，より簡易的な計算方法の開発が必要とされる。また， 本稿ではフォノンの界面透過確率を簡易的に取り扱ったが, 数値計算による正確な界面透過確率の導出方法の他，今後の 測定による構造と界面熱コンダクタンスの関係の知見も望ま れる。また，例えばシリコンに扔けるホウ素やリン等といっ 
たドーパントによってフォノンの輸送がどのように変化する かはこれまで厳密には求められていないため，そうした知見 も期待される.

\section{謝 辞}

本稿の内容の一部は日本学術振興会特別研究員制度 (249161), 科学研究費補助金 (2679009), および科学技術振興機 構さきがけの支援により得られた成果である。ここに記して 感謝の意を表す.

\section{文献}

1) A. Majumdar: "Thermoelectricity in semiconductor nanostructures”, Science, 303 (2004) 777-778.

2) T. C. Harman, P. J. Taylor, M. P. Walsh, B. E. LaForge: "Quantum dot superlattice thermoelectric materials and devices", Science, 297 (2002) 2229-2232.

3) A. I. Hochbaum, R. Chen, R. D. Delgado, W. Liang, E. C. Garnett, M. Najarian, A. Majumdar, P. Yang: "Enhanced thermoelectric performance of rough silicon nanowires", Nature, 451 (2008) 163-167.

4) A. I. Boukai, Y. Bunimovich, J. Tahir-Kheli, J. K. Yu, W. A. Goddard, J. R. Heath: "Silicon nanowires as efficient thermoelectric materials", Nature, 451 (2008) 168-171.

5) B. Poudel, Q. Hao, Y. Ma, Y. Lan, A. Minnich, B. Yu, X. Yan, D. Wang, A. Muto, D. Vashaee, X. Chen, J. Liu, M. S. Dresselhaus, G. Chen, Z. Ren: "High-thermoelectric performance of nanostructured bismuth antimony telluride bulk alloys", Science, 320 (2008) 634-638.

6) Y. C. Lan, B. Poudel, Y. Ma, D. Z. Wang, M. S. Dresselhaus, G. Chen, Z. F. Ren: "Structure Study of Bulk Nanograined Thermoelectric Bismuth Antimony Telluride", Nano Lett, 9 (2009) 1419-1422.

7) S. K. Bux, R. G. Blair, P. K. Gogna, H. Lee, G. Chen, M. S. Dresselhaus, R. B. Kaner, J.-P. Fleurial: "Nanostructured Bulk Silicon as an Effective Thermoelectric Material", Advanced Functional Materials, 19 (2009) 2445-2452.

8) K. Biswas, J. He, I. D. Blum, C. I. Wu, T. P. Hogan, D. N. Seidman, V. P. Dravid, M. G. Kanatzidis: "High-performance bulk thermoelectrics with all-scale hierarchical architectures", Nature, 489 (2012) 414-418.

9) X. Yan, G. Joshi, W. Liu, Y. Lan, H. Wang, S. Lee, J. W. Simonson, S. J. Poon, T. M. Tritt, G. Chen, Z. F. Ren: "Enhanced thermoelectric figure of merit of p-type half-Heuslers", Nano Lett, 11 (2011) 556-560.

10) G. Joshi, T. Dahal, S. Chen, H. Wang, J. Shiomi, G. Chen, Z. Ren: "Enhancement of thermoelectric figure-of-merit at low temperatures by titanium substitution for hafnium in n-type half-Heuslers Hf0.75-xTixZr0.25NiSn0.99Sb0.01", Nano Energy, 2 (2013) 82-87.

11) G. P. Srivastava: The physics of phonons, CRC Press, (1990)
29 and 185.

12) P. G. Klemens: "The Thermal Conductivity of Dielectric Solids at Low Temperatures-Theoretical", Proceedings of the Royal Society of London Series A, Mathematical and Physical Sciences, 208 (1951) 108-133.

13) K. Esfarjani, H. T. Stokes: "Method to extract anharmonic force constants from first principles calculations", Physical Review B, 77 (2008) 144112.

14) D. A. Broido, M. Malorny, G. Birner, N. Mingo, D. A. Stewart: "Intrinsic lattice thermal conductivity of semiconductors from first principles”, Applied Physics Letters, 91 (2007) 231922.

15) K. Esfarjani, G. Chen, H. T. Stokes: "Heat transport in silicon from first-principles calculations", Physical Review B, 84 (2011) 085204

16) J. Shiomi, K. Esfarjani, G. Chen: "Thermal conductivity of half-Heusler compounds from first-principles calculations", Physical Review B, 84 (2011) 104302.

17) T. Shiga, J. Shiomi, J. Ma, O. Delaire, T. Radzynski, A. Lusakowski, K. Esfarjani, G. Chen: "Microscopic mechanism of low thermal conductivity in lead telluride", Physical Review B, 85 (2012) 155203.

18) L. Lindsay, D. A. Broido, T. L. Reinecke: "Ab initio thermal transport in compound semiconductors", Physical Review B, 87 (2013) 165201.

19) G. A. Bird: Molecular gas dynamics and the direct simulation of gas flows, Oxford University Press, (1904) 203.

20) R. B. Peterson: "Direct Simulation of Phonon-Mediated HeatTransfer in a Debye Crystal", Journal of Heat TransferTransactions of the Asme, 116 (1994) 815-822.

21) S. Mazumder, A. Majumdar: "Monte Carlo Study of Phonon Transport in Solid Thin Films Including Dispersion and Polarization”, Journal of Heat Transfer, 123 (2001) 749-759.

22) D. Lacroix, K. Joulain, D. Lemonnier: "Monte Carlo transient phonon transport in silicon and germanium at nanoscales", Physical Review B, 72 (2005) 064305.

23) Q. Hao, G. Chen, M.-S. Jeng: "Frequency-dependent Monte Carlo simulations of phonon transport in two-dimensional porous silicon with aligned pores", Journal of Applied Physics, 106 (2009) 114321.

24) J. -P. M. Péraud, N. G. Hadjiconstantinou: "Efficient simulation of multidimensional phonon transport using energy-based variance-reduced Monte Carlo formulations", Physical Review B, 84 (2011) 205331.

25) J.-P. M. Péraud, N. G. Hadjiconstantinou: “An alternative approach to efficient simulation of micro/nanoscale phonon transport", Applied Physics Letters, 101 (2012) 153114.

26) W. A. Little: "The Transport of Heat between Dissimilar Solids at Low Temperatures", Canadian Journal of Physics, 37 (1959) 334-349.

27) E. T. Swartz, R. O. Pohl: "Thermal-Resistance at Interfaces", 
Applied Physics Letters, 51 (1987) 2200-2202.

28) P. K. Schelling, S. R. Phillpot, P. Keblinski: "Phonon wavepacket dynamics at semiconductor interfaces by moleculardynamics simulation”, Applied Physics Letters, 80 (2002) 2484-2486.

29) H. Zhao, J. B. Freund: "Lattice-dynamical calculation of phonon scattering at ideal Si-Ge interfaces", Journal of Applied Physics, 97 (2005) 024903.

30) Z. Tian, K. Esfarjani, G. Chen: "Enhancing phonon transmission across a $\mathrm{Si} / \mathrm{Ge}$ interface by atomic roughness: First-principles study with the Green's function method", Physical Review B, 86 (2012) 235304.

31) J. M. Ziman: Electrons and phonons: the theory of transport phenomena in solids, Oxford University Press, (2001) 456.
32) T. Suzudo, H. Kaburaki: "An evolutional approach to the numerical construction of polycrystalline structures using the Voronoi tessellation", Physics Letters A, 373 (2009) 44844488.

33) Z. Wang, J. E. Alaniz, W. Jang, J. E. Garay, C. Dames: “Thermal conductivity of nanocrystalline silicon: importance of grain size and frequency-dependent mean free paths", Nano Lett, 11 (2011) 2206-2213.

34) M. Sakata, T. Hori, T. Oyake, J. Maire, M. Nomura, J. Shiomi: submitted.

35) Z. Tian, K. Esfarjani, G. Chen: "Green's function studies of phonon transport across Si/Ge superlattices”, Physical Review B, 89 (2014) 235307. 